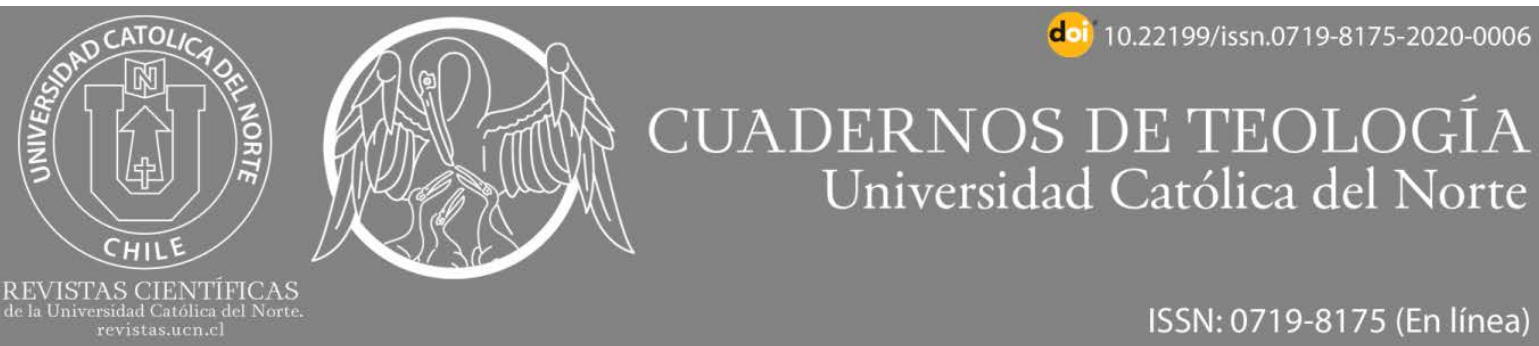

\title{
Desregulación y movilidad religiosa: dinamismo identitario al interior del campo cristiano-evangélico chileno
}

\section{Deregulation and religious mobility: identity dynamism inside the christian-evangelical chilean field}

\author{
Fabián Bravo Vega' (D) orcid.org/0000-0002-8720-2806 \\ 'Universidad San Sebastián. Santiago, Chile. Académico. Doctorando en Estudios Americanos, Instituto de \\ Estudios Avanzados, Universidad de Santiago de Chile. Becario ANID N²1200689. \\ fbravovega@gmail.com \\ (cc) BY
}

\section{Resumen:}

Se reflexiona sobre el campo cristiano-evangélico a través de un análisis de las dinámicas identitarias internas: adscripciones institucionales en relación a creencias teológicasdoctrinarias, reflexividad biográfica, significados en torno a la conversión y movilidad religiosa. En términos metodológicos la investigación se estructura a través de un enfoque que combina el enfoque cuatitativo con el cualitativo de manera consecutiva, la producción de información a través de un cuestionario online a través de sitios virtuales de alta visibilidad dentro del mundo cristiano-evangélico, Redes Sociales, a través de correo electrónico mediante la técnica de 'bola de nieve'; y trabajo de campo etnográfico con entrevistas en profundidad. Entre los resultados obtenidos se puede mencionar una gestión identitaria definida por la translocalización, las movilidades religiosas y rupturas biográficas resignificadas.

Palabras Clave: Protestantes chilenos; Desinstitucionalización; Conversión religiosa; Identidad translocalizada; Sociología de la religión.

\begin{abstract}
:
It reflects on the Christian-evangelical field through an analysis of internal identity dynamics: institutional ascriptions in relation to theological-doctrinal beliefs, biographical reflexivity, meanings around religious conversion and mobility. In methodological terms, the research is structured through an approach that consecutively combines the quantitative with the qualitative, the production of information through an online questionnaire through virtual sites with high visibility within the Christian-evangelical world, Social Networks, through email using the 'snowball' technique; and ethnographic fieldwork with in-depth interviews. Among the results obtained we can mention an identity management defined by translocation, religious mobilities and resignified biographical ruptures.

Keywords: Chilean protestant; Deinstitutionalization; Religious conversion; Translocalized identity; Sociology of religion.
\end{abstract}




\section{Introducción}

En la actualidad la religiosidad en Chile y América Latina experimenta un profundo proceso de transformación y crisis institucional, evidenciado principalmente en un fuerte declive de la identificación religiosa por parte de los creyentes. En un estudio realizado por el Pew Research Center (2014) acerca del cambio religioso en América Latina, mostró un decrecimiento sostenido del catolicismo desde un 94\% a comienzos del siglo XX hasta un $69 \%$ en 2014. En contraposición, los evangélicos han experimentado un incremento que va desde apenas un $1 \%$ hasta un $19 \%$ en el mismo lapso de tiempo mencionado.

Este escenario se da en un contexto de creciente desinstitucionalización (Algranti, Mosqueira y Setton, 2019) lo que implica una condición de incapacidad por parte de las instituciones para proveer un sentido de pertenencia, identidad y normatividad. Si bien en la literatura especializada la llamada "explosión" evangélica en América Latina se encuentra documentada desde finales de la década de los 60 (Lalive, 2009; Willems, 1967; Rolim, 1980) en la actualidad este crecimiento exponencial también ha visibilizado un cierto estancamiento, al menos en términos de adscripción y participación formales. En Chile, esta tendencia es aún más evidente (Centro de Estudios Públicos, 2018; Pontificia Universidad Católica y Adimark, 2018).

La dominación española en América Latina estableció un catolicismo hegemónico que si bien proveyó una matriz cultural integradora, posibilitó el origen a un sinnumero de formas sincréticas. Así, con la llegada del proyecto de la modernidad y los procesos de modernización el monopolio católico derivó en un paisaje religioso marcado por la pluralización de religiosidades, espiritualidades y alternativas de sentido rompiendo con la lógica de la secularización europea (Parker, 1993; Bastian, 2006; Casanova, 2007). De allí que, en las últimas décadas, las transformaciones socioculturales no han hecho más que acentuar el carácter plural de un campo religioso cada vez más complejo y difícil de pesquizar.

Por ello, este artículo busca analizar las dinámicas identitarias al interior del campo cristiano-evangélico chileno. Como hipótesis planteamos que dicho campo religioso se encuentra definido por el dinamismo, esto significa el movimiento de creencias, modos de acción, representaciones, subjetividades, disposiciones, prácticas y símbolos, lo que termina repercutiendo en la construcción y gestión de las identidades de los creyentes.

\section{Metodología y diseño de la investigación}

La investigación que se articula a partir de dos procesos consecutivos y complementarios: el primero desde un enfoque cuantitativo, el cual constó a partir de una muestra teórica no-probabilística, la que se obtuvo a través de una encuesta elaborada por medio de la plataforma Google Drive, desde finales de febrero hasta principios de abril de 2019. Dicha encuesta se confeccionó en base a los planteamientos de Charles Y. Glock sobre las dimensiones de religiosidad pero con modificaciones para efectos de los objetivos de nuestra investigación. Dichas dimensiones son: experiencia religiosa, ritualista, ideológica, 
intelectual y consecuencial de las convicciones religiosas (Glock citado en Matthes, 1971, p. 168).

La encuesta se estructura de 46 preguntas que fueron respondidas en un tiempo aproximado de entre 10 a 15 minutos, su difusión principal fue a través de Redes Sociales de alta visibilidad en el mundo cristiano-evangélico chileno y por medio de la técnica de 'bola de nieve', a través de correo electrónico y WhatsApp. Este procedimiento corresponde a una técnica de muestreo no probabilístico utilizada cuando no se tiene información suficiente para determinar un marco muestral. De esta manera, es posible dimensionar el tamaño de un determinado grupo de sujetos, además de proporcionar un conocimiento global de los mismos, tales como espacios de sociabilidad y diferentes tipos de vínculos (Alloatti, 2014). Por esta razón, la investigación corresponde a un tipo de estudio exploratorio compuesto por 473 casos los cuales fueron procesados y analizados mediante el software SPSS. Dede esta perspectiva, el propósito de generar una encuesta consistió precisamente en estructurar una muestra teórica no probabilística que buscó descubrir ciertos perfiles de creyentes, mediante el análisis de determinadas variables que sustentaron dicha muestra.

Posteriormente, el enfoque cualitativo se articuló a partir de un tipo de muestreo intencional compuesto por 6 ( 4 hombres y 2 mujeres) adultos cristiano-evangélicos chilenos de distintas denominaciones de un rango etario desde los 29 a los 35 años, sujetos que fueron seleccionados a partir de la primera etapa recién descrita. En cuanto a la técnica de producción de información se utilizó la entrevista en profundidad, también llamada entrevista individual abierta semidirectiva (Valles, 1999, p.184). Fundamentalmente se define como: "una técnica de investigación social que pone en relación de comunicación directa cara a cara a un investigador/entrevistador y a un individuo entrevistado con el cual se establece una relación peculiar que es dialógica, espontánea, concentrada y de intensidad variable" (Gaínza, 2006, pp. 219-220).

En síntesis, las dimensiones identitarias principales que abordamos a través de estos enfoques son adscripciones institucionales en relación a creencias teológicas-doctrinarias, reflexividad biográfica, significados en torno a la conversión y movilidad religiosa. 


\section{Transformaciones estructurales de la religiosidad chilena contemporánea}

En términos contextuales, un primer elemento a considerar dice relación con la evolución de la religiosidad en Chile durante el siglo XX, la cual se presenta a continuación:

\section{Gráfico 1}

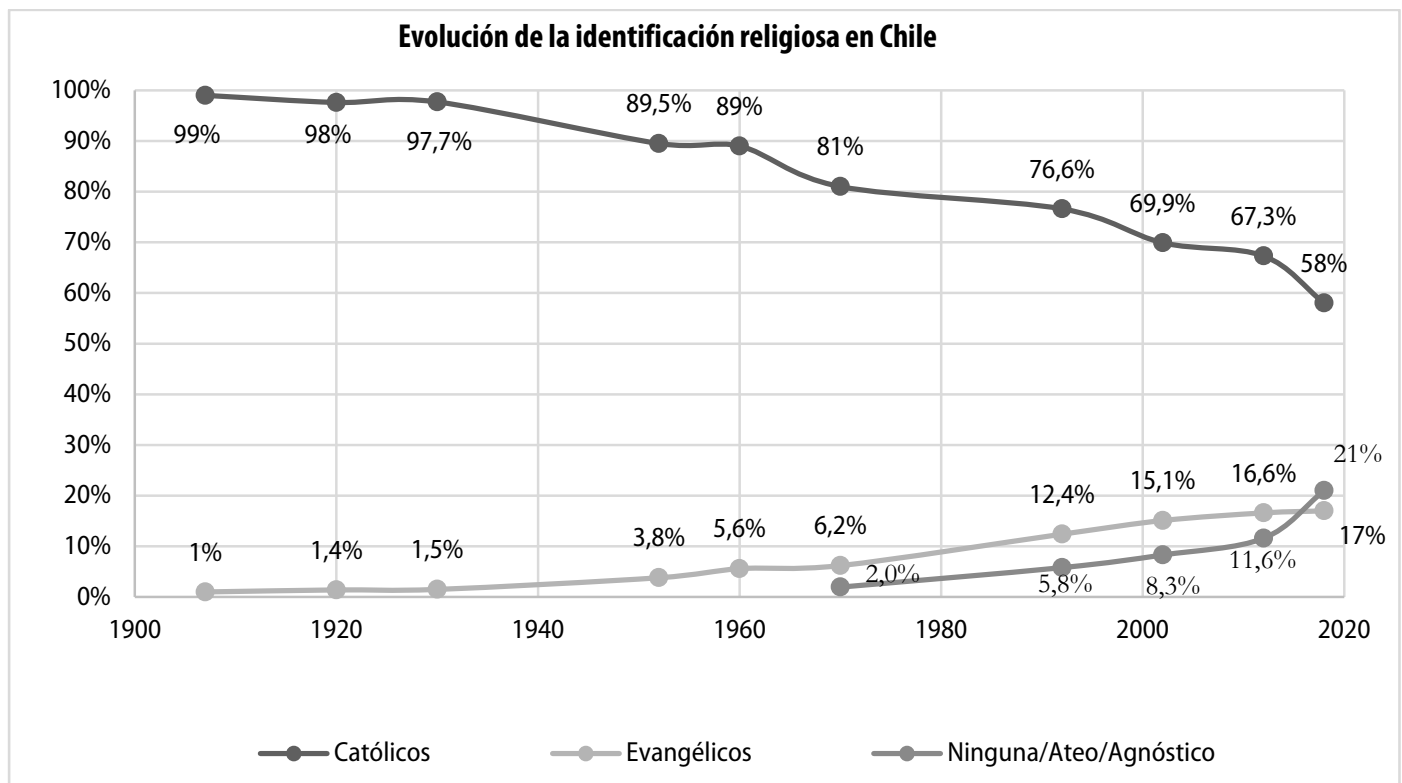

(Fuentes: Instituto Nacional de Estadísticas, 2002 y 2012; Hinzpeter y Lehmann, 1999; Corvalán, 2009; Valenzuela, Bargsted y Somma, 2013; Pontificia Universidad Católica y Adimark, 2018).

Durante este siglo vemos cómo el campo religioso expresa un evidente declive de la identificación católica de más de un 40\% en menos de 100 años. En cambio, se aprecia un crecimiento sostenido de evangélicos a partir de la década de 1960, registrando en 2018 un $16 \%$ de la población. Sin embargo, teniendo en cuenta su comportamiento, se puede decir que en los últimos años la tendencia al crecimiento presenta un estancamiento. También se oberva la emergencia y crecimiento de una categoría cada vez más relevante, nos referimos a los "sin religión"1.

Este escenario complejo sugiere un proceso de privatización pero por sobre todo de desinstitucionalización, puesto que a pesar de que crece el número de rechazo a la religión organizada, la creencia en Dios sigue manteniendo altos niveles (CEP, 2018). Entre los factores que inciden en el aumento a la desafiliación se encuentran el peso de las nuevas generaciones y las tensiones surgidas en el desarrollo de la transmisión de la fe (González, 2018, p. 8).

Se ha dicho que, a lo largo del siglo XX, tanto fuerzas y factores exógenos como endógenos propiciaron una serie de transformaciones en la fisonomía del campo religioso

\footnotetext{
${ }^{1}$ No incluimos en este registro a "otras religiones" (budismo, islamismo, judaísmo, etc.), las que oscilan entre un $4 \%$ y $3 \%$ del total.
} 
en las sociedades contemporáneas latinoamericanas bajo los efectos de los procesos de modernización (Suárez citado en Bahamondes González, 2012, p. 111).

Históricamente, el campo religioso cristiano-evangélico se encuentra fuertemente representado por una forma de pentecostalismo clásico (o también llamado criollo), el que ha sido vinculado a determinados procesos de modernización y a un determinado grupo social (Mundo Popular) (Míguez, 2000, p. 58). No obstante, existen también otras tradiciones y denominaciones como los derivados del protestantismo histórico (luteranos, presbiterianos, metodistas, bautistas, etc.) y otros grupos del mundo pentecostales como el pentecostalismo misionero y los llamados neopentecostales (Bahamondes González y Marín Alarcón, 2014).

\section{Aproximación mediante una propuesta de categorización}

Este nivel de diversificación plantea una primera problemática para la aproximación a la identidad colectiva evangélica (para algunas categorizaciones interesantes por oleadas en la región véase: David Stoll, 2002, p. 18 e Hilario Wynarczyk, 1993). Esto quedó en evidencia en la gran cantidad de denominaciones, congregaciones, iglesias, misiones evangelísticas y ministerios apostólicos a los cuales los creyentes se identificaron como miembros activos en la encuesta virtual realizada para esta investigación ${ }^{2}$. Para Cantón Delgado (2002) gran parte de dicha problemática se debe al carácter expansivo en su dinámica de reproducción. Por esta razón proponemos una clasificación propia con la finalidad de situar la identidad colectiva cristiano-evangélica desde una comprensión más global y por encima de condicionantes orgánico-burocráticos. Nuestra hipótesis sostiene que, al aplicar ciertos criterios de orden teológico-históricos, se genera entrecruzamientos entre los distintos colectivos, independientes de su forma organizativa. Asimismo, esta propuesta busca demostrar la capacidad dinámica y diversificadora de las creencias por encima de los parámetros institucionales.

La categorización que presentamos se compone de 3 macro grupos: el primero de ellos, denominado 'Evangélicas pneumatocéntricas', aglutina congregaciones que manifiestan o promueven abiertamente los Dones o Carismas del Espíritu Santo, desde el pentecostalismo clásico o tradicional ${ }^{3}$, el pentecostalismo misionero ${ }^{4}$, incluyendo los movimientos carismáticos evangélicos y el llamado neopentecostalismo ${ }^{5}$. Tal como se evidencia, esta primera categoría presenta un 39\% del universo total de encuestados

\footnotetext{
${ }^{2}$ Como se mencionó en la introducción, la encuesta se compuso en base a una muestra total de 473 casos: 51 , $2 \%$ de los encuestados corresponden a hombres y $48,8 \%$ a mujeres. Distribuidos de la siguiente forma a lo largo del país: 9,6\% correspondiente a la zona norte, un 59, 4\% pertenecientes a la zona central (Región Metropolitana y de Valparaíso) y un $31 \%$ a la zona sur de Chile.

${ }^{3}$ Esta subcategoría comprende los avivamientos y pentecostalismos de origen criollo, principalmente congregaciones tales como la Iglesia Evangélica Pentecostal, la Iglesia Metodista Pentecostal y el pentecostalismo unicitario, conocida comúnmente como iglesias "Solo Jesús".

${ }^{4}$ Bajo esta subcategoría se concentran, principalmente, aquellos pentecostalismos provenientes desde Estados Unidos o Europa, como es el caso más emblemático de las Asambleas de Dios.

${ }^{5}$ Esta categoría incluye iglesias locales de denominación carismática, criollas y de origen extranjero, como el caso de la Iglesia La Viña y también una larga lista de congregaciones autónomas y ministerios evangelísticos que comparten entre otros aspectos doctrinarios propios del pentecostalismo, un énfasis en la Teología de la Prosperidad y la Guerra Espiritual.
} 
chilenos ( $\mathrm{N}=473$ ), lo que se condice con una gran cantidad de estimaciones que indican que la presencia pentecostal-carismática es la mayoría del total de lo que constituye el mundo cristiano-evangélico como ocurre a nivel regional (Le Bot citado en Pédron-Colombani, 2004).

Le sigue la macrocategoría, denominada 'Protestantes históricas y reformadas' aquí encuentran convergencia iglesias de origen europeo herederas de la Reforma Protestante del siglo XVI, como la Iglesia Luterana y las de corte calvinista-reformadas como la Iglesia Presbiteriana y Anglicana. Asimismo, se incluyen las llamadas mainline churches (Jaimes Martínez, 2007) como el metodismo y el bautismo de raíz norteamericano-, la que abarca el $30 \%$ del total de encuestados. Por último, se agrupó al resto de encuestados bajo la categoría de 'Evangélicas convencionales y plurales' ${ }^{6}$ con un $20 \%$, las que incluyen diversas congregaciones que no responden a los criterios recién mencionados. Son organizaciones que poseen como rasgo común el énfasis en la experiencia religiosa evangélica sin necesidad de entrar en grandes debates teológicos ${ }^{7}$. Asimismo, es necesario indicar que solamente un $11 \%$ no contestó o no supo decir a qué denominación pertenece en la actualidad. Así, esta propuesta tuvo como objetivo visibilizar la eficacia de la influencia teológica-institucional en la construcción de una identidad cristiano-evangélica, la que a continuación será tensionada con otras variables.

\section{Reflexividad autobiográfica y discipulado en el sujeto cristiano- evangélico chileno}

Un aspecto matricial en la identidad religiosa individual del creyente guarda relación con la capacidad de evaluar su condición de cristiano-evangélico, y de su autopercepción proyectada hacia el resto de la sociedad, es decir a los no-creyentes. Ante esto, se les preguntó a los encuestados de qué manera se definen ante aquellos que no comparten su cosmovisión, siendo la alternativa con mayor frecuencia la categoría "cristiano (a)" con un $68 \%(\mathrm{~N}=473)$.

\footnotetext{
${ }^{6}$ Esta macrocategoría si bien comprende un sinnúmero de denominaciones e iglesias del más diverso tipo, muchas de ellas provienen de alguna de las tradiciones anteriores pero su estatus actual es completamente autónomo, además se caracterizan por la ausencia de manifestar, formal y abiertamente, la creencia en los Dones del Espíritu. En este desconcierto categórico es posible mencionar: La Alianza Cristiana y Misionera, Iglesia Bíblica, la Iglesia de Hermanos Libres, El Ejército de Salvación, entre otras.

7 Dentro del mundo cristiano-evangélico existe dos grandes corrientes teológicas: el calvinismo y el arminianismo, ambas difieren principalmente en el problema de la Soberanía de Dios y la Responsabilidad Humana (soteriología). La primera de estas tradiciones suele estar vinculada a doctrinas cesacionistas y posiciones amilenialistas y posmilenialistas en relación a los últimos tiempos (escatologías), mientras que la segunda se le relaciona con doctrinas continuistas y posiciones premilenialistas y dispensacionalistas, aunque existen excepciones a estas correspondencias.
} 
Tabla 1

\begin{tabular}{|c|c|c|c|c|c|}
\hline \multirow{2}{*}{$\begin{array}{c}\text { ¿Cómo te defines } \\
\text { frente a los no- } \\
\text { creyentes? }\end{array}$} & \multicolumn{5}{|c|}{ Macrocategorías } \\
\cline { 2 - 6 } & $\begin{array}{c}\text { Evangélico } \\
\text { pneumatocéntrico }\end{array}$ & $\begin{array}{c}\text { Protestantes } \\
\text { histórico y } \\
\text { Reformado }\end{array}$ & $\begin{array}{c}\text { Evangélico } \\
\text { convencional y } \\
\text { plural }\end{array}$ & $\begin{array}{c}\text { Ninguna/ } \\
\text { No sabe }\end{array}$ & Total \\
\hline Creyente & $2 \%$ & $1,4 \%$ & $1,1 \%$ & $10 \%$ & $2,3 \%$ \\
\hline Cristiano & $68 \%$ & $66 \%$ & $70 \%$ & $73 \%$ & $68,2 \%$ \\
\hline Evangélico & $24 \%$ & $11,1 \%$ & $19 \%$ & $8 \%$ & $17,2 \%$ \\
\hline Protestante & $6,6 \%$ & $18,1 \%$ & $7,4 \%$ & $10 \%$ & $11 \%$ \\
\hline Otra & $0 \%$ & $3,5 \%$ & $3,2 \%$ & $0 \%$ & $1,7 \%$ \\
\hline Total & $100 \%$ & $100 \%$ & $100 \%$ & $100 \%$ & $100 \%$ \\
\hline
\end{tabular}

Antropológicamente, abordar la identidad cristiana-evangélica en la modernidad implica situar al creyente en un escenario donde el término cristiano designa una cosmovisión antes que una identidad colectiva. En otras palabras, es entendida como una marca de autodefinición ante el mundo secular por parte de los mismos sujetos, lo que se describen así mismos como cristianos y, posteriormente, como protestantes, evangélicos o la denominación que según corresponda, ya que estos últimos conceptos corresponden a identificaciones situadas a contextos sociohistóricos específicos, en cambio "ser cristiano" es una forma de ontológica de ser y estar en el mundo.

Este proceso de identificación incluye la construcción de otro-como-distinto (alteridad) que utiliza como unidad de criterio al "no-creyente" y sindicado dentro del "Mundo", disociación tradicionalmente vinculada al mundo pentecostal pero presente en otros contextos cristiano-evangélicos. Al mismo tiempo, reconoce la existencia de una pluralidad con sus límites y posibilidades de acción institucionalizada:

Uno de los elementos fundamentales en las interacciones individuales con sujetos pertenecientes a diferentes grupos adscriptivos es la capacidad de los individuos para descodificar los símbolos, actitudes y conducta de los otros, que se consigue a través de repertorios clasificatorios estereotipados a los que se denomina etiquetas sociales (Pujadas citado en Revilla y Carmona, 2002, p. 76).

De la misma manera, en la configuración del self cristiano-evangélico no solamente concierne el autoconcepto hacia el otro, en este caso, hacia el no-creyente, sino también hacia sus propios hermanos en la fe. Bajo este aspecto, es importante considerar el volumen e influencia del pentecostalismo en el campo evangélico de América Latina. Esta pentecostalización nos da algunas directrices para entender por qué solamente un $6,6 \%$ de los creyentes pertenecientes a la macrocategoría 'Evangélicas pneumatocéntricas' (pentecostales y evangélicos-carismáticos) se identifica ante los otros como 'protestante' y sólo un $11,1 \%$ de los creyentes 'Protestantes históricos y reformados' se considera 'evangélico'. En ambos casos se aprecia un distanciamiento que obedece a razones históricas y teológicas, ya que por un lado:

En el interior de las iglesias [pentecostales] la renuncia al nombre protestante se da muchas veces en términos agresivos y viscerales, porque se le identifica con una tradición abstracta, fría e intelectualizante. (Cervantes-Ortíz, 2003, p. 129). 
En tanto que, desde las iglesias herederas directas de la Reforma "hay mucha resistencia (...) en admitirlos como «miembros de la familia»" (Mendonça citado en Jungblut, 2015, p. 97), eso explicaría por qué tienden a identificarse muy poco como evangélicos ya que en términos generales, para la Opinión Pública ser evangélico es sinónimo de ser pentecostal. De allí que esta configuración bipolar de la religiosidad cristiana-evangélica obedece en parte a factores de orden históricos, donde dichas religiosidades adquirieron una identidad contrapuesta que se expresa en la oposición razón/emoción:

Mientras los primeros [protestantes históricos] eran una religión de lo escrito, una religión cívica y racional, los segundos [pentecostales] son una religión de la oralidad, una religión emocional, efervescente y de tradición endógena. Mientras que los primeros eran portadores de prácticas inculcadoras de valores democráticos a través del civismo y la educación en particular, los segundos reproducen modelos caciquiles y caudillescos de control religioso y social (Bastian, 2006, p. 52).

Asimismo, al explorar la evaluación de la fe de los creyentes resulta interesante apreciar una distribución de más del $50 \%(\mathrm{~N}=465)^{8}$ que se identifica con la sentencia "Trato de cultivar una relación con Dios pero me cuesta seguir la "vida cristiana»", como se aprecia a continuación:

Tabla 2:

\begin{tabular}{|c|c|c|c|c|c|}
\hline \multirow{2}{*}{$\begin{array}{l}\text { Evaluación de la fe por } \\
\text { macrocategorías } \\
\text { ¿Cuál es tu situación actual } \\
\text { respecto a tu fe? }\end{array}$} & \multicolumn{5}{|c|}{ Macrocategorías } \\
\hline & $\begin{array}{l}\text { Evangélicas } \\
\text { pneumato- } \\
\text { céntricas }\end{array}$ & $\begin{array}{l}\text { Protestantes } \\
\text { históricas y } \\
\text { reformadas }\end{array}$ & $\begin{array}{l}\text { Evangélicas } \\
\text { convencionales y } \\
\text { plurales }\end{array}$ & $\begin{array}{l}\text { Ninguna/ } \\
\text { No sabe }\end{array}$ & Total \\
\hline $\begin{array}{l}\text { Me encuentro alejado de la «vida } \\
\text { cristiana» pero espero volver en } \\
\text { algún momento }\end{array}$ & $3 \%$ & $2 \%$ & $1 \%$ & $6 \%$ & $3 \%$ \\
\hline $\begin{array}{l}\text { A menudo hay situaciones y } \\
\text { experiencias que hacen cuestionar } \\
\text { seriamente mi fe }\end{array}$ & $2 \%$ & $1 \%$ & $3 \%$ & $12 \%$ & $3 \%$ \\
\hline $\begin{array}{l}\text { Sigo creyendo pero ya no siento la } \\
\text { cercanía, motivación o las } \\
\text { sensaciones que tuve en un } \\
\text { principio }\end{array}$ & $6 \%$ & $9 \%$ & $10 \%$ & $14 \%$ & $8 \%$ \\
\hline $\begin{array}{l}\text { Trato de cultivar una relación con } \\
\text { Dios pero me cuesta seguir la } \\
\text { «vida cristiana» }\end{array}$ & $57 \%$ & $58 \%$ & $57 \%$ & $45 \%$ & $56 \%$ \\
\hline $\begin{array}{l}\text { Tengo una relación profunda y } \\
\text { activa con Dios que crece con el } \\
\text { tiempo }\end{array}$ & $32 \%$ & $30 \%$ & $29 \%$ & $23 \%$ & $30 \%$ \\
\hline Total & $100 \%$ & $100 \%$ & $100 \%$ & $100 \%$ & $100 \%$ \\
\hline
\end{tabular}

Esta opción se encuentra de manera transversal en todas las macrocategorías, lo que da cuenta de una auto-representación de la existencia en permanente conflicto, vinculada a la oposición carne/espíritu, la cual es noción ya presente en el cristianismo primitivo y desarrollado en los basamentos del protestantismo por Lutero, con la doctrina de los dos reinos como un factor decisivo en la conformación de un ámbito íntimo en el individuo

\footnotetext{
${ }^{8}$ Hubo 8 casos perdidos que no se consideraron para esta pregunta, por esta razón difiere del tamaño total de la muestra de encuestados $\mathrm{N}=473$.
} 
occidental, además se aprecian no solamente las bases para la emancipación individual de los dispositivos de control institucional de la Iglesia Católica sino que a la vez, asoma la construcción de una naturaleza bidimensional en el Ser Humano, es decir, el "hombre interior" y el "hombre externo" (Lutero, 1520). Por ende, esta es una religiosidad indisociable al orden moderno. Asimismo, el examen de conciencia alude a una resignificación de este ámbito íntimo como un dominio de reflexividad sobre la salvación misma del alma humana, aspecto que también forma parte de la herencia de la Reforma.

Desde la teoría del sujeto, la autopercepción de vivir un cristianismo siempre al debe guarda coherencia con una condición propia del proceso de arquitectura identitaria, en el cual la estructuración del individuo en sujeto de sí mismo se presenta como un objetivo prácticamente inalcanzable (Bajoit citado en Araya Silva, 2017, p. 32).

Sociológicamente, la apreciación de una fe conflictual en la práctica, se vincularía a un proceso inherente a la modernidad, nos referimos a una experiencia de derelicción que separa la "realidad" de la "verdadera vida". En otras palabras, corresponde a un sentimiento de irrealidad en el proyecto de vida que se ha escogido vivir. Esta condición inalcanzable se instala como una de las mayores, sino la mayor, tensión existencial actual (Martuccelli, 2007, p. 105). Así, esta evaluación se presenta como un proyecto siempre al debe, determinado por un sistema de valores relativos a la "santificación" del cristiano-evangélico, es decir, un proceso de perfeccionamiento progresivo que abarca todas las denominaciones.

Esta reflexividad adquiere una importancia primordial al ser un ejercicio permanente que constriñe al creyente para mantenerse dentro de los límites simbólico-prácticos de lo que significa "ser cristiano". Opera como el soporte del self, entendido como el concepto de sí mismo:

Yo creo que se tiene que congregar en un lugar o al menos estar en proceso o siempre estar en el corazón de él: '¿dónde me voy a congregar ahora?' o ir a estudiar a otro lado: Ok, 'Dónde, a qué iglesia voy a asistir?' Que un tipo se conforme solamente con asistir a un grupo bíblico porque su iglesia está en Arica y él está estudiando ahí en Concepción, no sé si realmente es un tipo cristiano (...) Otra es que predique, tiene que compartir su $f e(. .$.$) Tiene que orar y principalmente$ yo creo que debe tener un buen un testimonio, o se él tiene que buscar a Dios y eso se tiene que manifestar en obras, obras entiéndase en una vida regenerada, un lenguaje diferente, una forma de pensar diferente, un actuar diferente, va en contra de la corriente ese tipo, que realmente dice ser cristiano. Si es cristiano, sigue a Cristo, y el cristiano va contra la corriente.

Adicionalmente, el discipulado posibilita al creyente la interiorización de la religiosidad que impacta en su autoconcepto $y$, al mismo tiempo, constituye el fundamento de la reproducción social al interior de las iglesias. Este tipo de socialización corresponde a la manifestación de un tipo de poder pastoral propia del protestantismo.

\footnotetext{
${ }^{9}$ Informante clave 1: hombre, 30 años, Licenciado en Física, ex participante activo de GBU. Miembro de Iglesia Carismática.
} 
La dirección de la conciencia evidenciada, desde orientaciones normativas hasta una obediencia total, podemos comprenderla como una técnica política de individualización (Foucault, 2014), caracterizada a través de los principios de sumisión, paciencia, pasividad y humildad. Significa la búsqueda de una verdad ubicada en sí mismo, la cual debe ser expresada de manera analítica a un otro en forma de confesión o de fragmentos biográficos que son resignificados dentro de una densa red de afectividades.

[El pastor] me estuvo discipulando junto con otro amigo (...) nos juntábamos los 3 y fue muy bacán po, fue muy bacán. Ahí yo crecí mucho en poquito tiempo con él. Fue muy al hueso, expuso mi corazón y como que empecé a entender verdades del Evangelio que no había comprendido hasta el momento ${ }^{10}$.

Subyace en todo este proceso la gran problemática de la articulación la gestión relacional del sí: la conciliación entre la realización personal y el reconocimiento social para lograr una consonancia existencial (Bajoit, 2003). Lo que en otras palabras significa las tensiones suscitadas a partir de las expectativas sobre el rol que adquiere el creyente en la congregación con las pretensiones de realización personal. Para Ossa (2011) este hecho constituye uno de los grandes problemas actuales de la identidad pentecostal.

Dicha tensión constituye una de las claves de acceso tanto los conflictos de la identidad individual como también la comprensión de las dinámicas normativas de las instituciones. Desde lo individual, este conflicto puede derivar en la deserción de la iglesia, la relativización del compromiso, una adscripción paralela a otra congregación o la supresión de las aspiraciones de autorrealización (Ossa, 2011, pp. 163-164). Asimismo, desde lo institucional el conflicto tiende a resolverse con la flexibilización de las exigencias al interior de buena parte de las congregaciones (Lindhartd, 2016) pero también existen otras que, utilizando los conceptos del Rational Choice, refuerzan sus niveles de exigencias Strictness- como una forma de asegurar el compromiso de sus miembros y filtrar los llamados free-riders, es decir, aquellos creyentes que solamente consumen bienes religiosos sin contribuir a su producción (Frigeiro, 2000, p. 38).

En síntesis, la reflexividad autobiográfica constituye un pilar fundamental de lo que intentamos dilucidar como la identidad cristiano-evangélica, debido a su importancia a la hora de configurar un self o concepto de sí mismo, que dentro de esta cosmovisión religiosa pendula desde una visión pesimista de la vida, heredera del puritanismo protestante, a posiciones que la exaltan como en el llamado neopentecostalismo. Asimismo, la importancia de la autoevaluación de la fe revela la capacidad dotar de sentido al momento de configurar una narrativa biográfica. Junto a ello, una identidad tensionada entre las expectativas del rol dentro de la comunidad y las aspiraciones de realización personal.

\section{Identidad y procesos de conversión}

La identidad religiosa cristiano-evangélica tiene como eje articulador del relato autobiográfico la experiencia de conversión donde el sujeto interioriza un sistema de

${ }^{10}$ Informante clave 2: hombre, 32 años, Arquitecto, Asesor de campo en GBU, miembro de Iglesia Anglicana. 
creencias como el fundamento de su existencia. En las ciencias sociales, esta problemática ha sido abordada desde diversos enfoques teórico-analíticos, uno de los más clásicos corresponde al llamado "modelo de la privación" y que básicamente sostiene que los conversos son motivados por una situación de precariedad o carencia (Garma Navarro, 2018, p. 101). Sin embargo, esta perspectiva explica solo parcialmente un fenómeno mucho más complejo.

Tradicionalmente esta vivencia se relaciona con un tipo de narrativa determinada, nos referimos al tipo paulino ${ }^{11}$, para Garma Navarro (2018) esta es la forma de conversión más anhelada y valorada dentro del mundo pentecostal. La importancia de esta forma narrativa recae en su cualidad para proveer un modelo de relato experiencial ordenado y lineal, el cual es legitimado por la colectividad que lo admite (pp. 104-107). En este sentido, constituye una experiencia transformadora, una ruptura en esta linealidad autobiográfica (Canales, 2011).

No obstante, cuando ampliamos el análisis a otras tradiciones cristiano-evangélicas y también cuando constatamos las distintas variantes de pentecostalismo actuales, vemos que este hecho no necesariamente constituye un hito o coyuntura concreta, sino que puede ser el fruto de una resignificación de experiencias que se expresan como un "proceso de conversión". En el contexto de la construcción de una trayectoria de conversión (conversion careers), a pesar de que el paradigma paulino ha tenido amplia difusión no sólo en el pentecostalismo sino también en el mundo cristiano-evangélico en general, no constituye el único rito de iniciación para el creyente. Weber, conceptualiza este nuevo nacimiento con un proceso de largo alcance conocido como santificación: El fenómeno de la santificación puede aparecer como un proceso de purificación progresiva o como una transformación repentina de espíritu (Metánoia), como un "renacimiento" (Weber, 1997, pp. 201-202).

Esta particularidad se hace patente cuando analizamos la trayectoria de movilidad de creencias. Entre los resultados obtenidos llama la atención cómo la identidad cristianoevangélica se configura, en algunos casos, a partir de una determinada matriz de religiosidad previa ya sea generalmente católica o la misma evangélica. Asimismo, de la matriz evangélica emerge una categoría que se asume así misma como "cristianos desde siempre" ('Siempre he sido cristiano (a)-evangélico (a) ') con un 28\% ( $\mathrm{N}=473$ ) del total de respuesta. Esta última, se observa como una condición biográfica que representa una ruptura con el paradigma paulino de conversión tradicional dentro del mundo cristianoevangélico ${ }^{12}$.

En el registro cualitativo, se observa en aquellos casos en los cuales existe un contexto de religiosidad practicante, es decir, de familias creyentes, tanto evangélicas como católicas, la conversión se asemeja a un proceso de autoconciencia sobre el estado actual de la vida y su proyección hacia el futuro:

\footnotetext{
"Llamado así en relación a la conversión experimentada por Pablo de Tarso, relatada en el Nuevo Testamento, quien, de ser un perseguidor y asesino de cristianos, pasó a ser uno de los pilares fundamentales de esta religión luego de tener un encuentro sobrenatural con Jesucristo.

${ }^{12}$ Además de lo anterior, cabe destacar la fuerte presencia de sujetos que antes de convertirse se consideraban "espirituales sin religión", lo que constituiría una de las expresiones más representativas de lo que hemos desarrollado como la desinstitucionalización de lo religioso.
} 
$Y$ después en $2^{\circ}, 3^{\circ}$ Medio vino el tiempo en el colegio, cuando vi cómo el Señor transformó a un amigo y todo, ahí entendí que no (...) Todavía no era, no había sido transformado por el Señor, no me había entregado a Él, como que ahí ese concepto de Salvación recién se apareció ahí. Ahí yo pude decir "yo soy cristiano", ahí recién con toda la Ley, es decir, con toda la identidad ${ }^{13}$.

En este caso, nuestro informante clave fue nacido y criado en un contexto evangélico, nunca hubo un cambio drástico de estilo de vida tal como se suele entender la conversión bajo el modelo paulino ("yo antes era así... pero luego conocí al Señor y mi vida cambió").

En suma, la conversión coyuntural o procesual implica un posicionamiento de parte del sujeto que lo lleva a la resignificación de su autoconcepto y a una reorientación de su acción en un contexto dado. Asimismo, las trayectorias biográficas analizadas presentan patrones y modelos de conversión: del tipo paulino, modelos discontinuos, no lineales y regresivos, y también trayectorias directamente ausentes de conversión

\section{Identidades religiosas translocalizadas}

Una de las claves para la comprensión de la identidad cristiano-evangélica actual se encuentra en los procesos de movilidad interna. Estos se dan en contexto globalizador donde fluyen, coexisten y negocian diversos elementos tanto autóctonos como foráneos de las distintas religiosidades y que, de alguna forma, alteran las maneras de percibir y construir las identidades religiosas (Roy, 2010; De la Torre, 2008). Las maneras actuales de localizar las identidades religiosas operan menos ligadas al territorio, a las instituciones, a los factores biológicos como la raza, y emergen localizaciones alternativas, como son la locación global (multinacional), la locación virtual (en la web), la locación cósmica (ejemplo en New Age), e interior (espiritualidad subjetivizada) (Barker, 2006) (De la Torre, 2008, p. 51).

En el cristianismo-evangélico este rasgo queda patente al observar cómo las identidades no se encuentran supeditadas a elementos socioculturales como las condiciones socioeconómicas y la marginalidad en el pentecostalismo, la ascendencia a un cierto origen étnico como en los protestantismos históricos o alguna vinculación institucional por tradición familiar, sino más bien se articulan bajo formas de translocalización de lo religioso, es decir, localizaciones a diversas escalas, dimensiones de la conciencia y la realidad social:

Después llegué a un libro de John Piper que se llama 'Sed de Dios'y ahí con ese libro fue como 'ya, sí, realmente este es el Dios que conozco, como que es muy distinto al Dios que me han mostrado', por así decirlo. No sé si es que me han mostrado pero como que yo veo que las otras personas conocen ¿me entiendes? Y ahí yo empecé una búsqueda más intensa todavía, de leer más cosas de él, de ver sus predicas en Internet y todo. Entonces ahí yo me empecé a dar cuenta que la iglesia donde yo iba se predicaba muy poco de ese

\footnotetext{
${ }^{13}$ Informante clave 3: hombre, 29 años, Ingeniero, ex líder del Ministerio Águilas de Jesús, miembro de Iglesia Metodista.
} 
Dios, como que se predicaba nada así en verdad (...) yo venía de un mundo donde nadie conocía esta otra cosa, como lo que yo descubrí en ese momento ${ }^{14}$.

En este fragmento se observa cómo la identidad religiosa se traduce en un proceso espiritual intradirigido, es decir, una localización introyectada que va generando una disociación con la institucionalidad a la cual esta informante clave perteneció. De esta manera, podemos sostener que la translocalización constituye una condición de posibilidad para fenómenos muy recientes como la pentecostalización del protestantismo históricoreformado - el primero de ellos asociado a demandas de intelectualización motivado por generaciones de evangélicas con mayores niveles de escolaridad en comparación con las anteriores (Parker, 2005). y, también, la calvinización del pentecostalismo, casos emblemáticos en Chile como la Iglesia La Trinidad, en la Región Metropolitana, de denominación anglicana-reformada, tradicionalmente cesacionista, dio un giro hacia el carismatismo. De manera inversa, la Iglesia Cristiana La Serena, norte de Chile, la cual comienza siendo carismática, termina abrazando las raíces calvinistas-reformadas de las Doctrinas de la Gracia (Bravo Vega, 2017).

\section{Tránsitos y migraciones internas: factor dinamizador y desregulador de las identidades}

La translocalización de lo religioso demarca un escenario complejo donde la religiosidad contribuye a definir un proyecto de vida. Ahora bien, sabemos que este proceso se desarrolla en un entramado existencial definido por el movimiento. En este sentido, emerge el fenómeno de la 'movilidad denominacional' como factor dinamizador y desregulador de las identidades. Los giros biográficos son posibilitados por experiencias de rupturas, en la religiosidad cristiano-evangélica estas vivencias se conciben como formas de poner a prueba -en el sentido bíblico del término- la propia fe, así como una instancia para "madurar" espiritualmente.

El término 'movilidad denominacional' proviene de una derivación del concepto "migración religiosa" de Garma Navarro (2004) pero modificado para aplicarse al tránsito dentro de un mismo sistema de creencias:

... idea de una transformación de las creencias y prácticas relacionadas con lo sagrado de parte de un individuo a través de un contacto intenso que experimenta con manifestaciones religiosas, espirituales y eclesiales diferentes y que implica modificaciones en sus experiencias y formas de vivir, cuando menos por un periodo determinado. (p. 204)

Ahora bien, en primera instancia conviene establecer cuál es la importancia que esta movilidad constituye para la configuración de la identidad cristiana-evangélica, veamos si este fenómeno es empíricamente relevante:

\section{Gráfico 2:}

\footnotetext{
${ }^{14}$ Informante clave 4: mujer, 35 años, actriz, ex misionera del Ministerio Vida Estudiantil, Miembro de Iglesia Anglicana.
} 


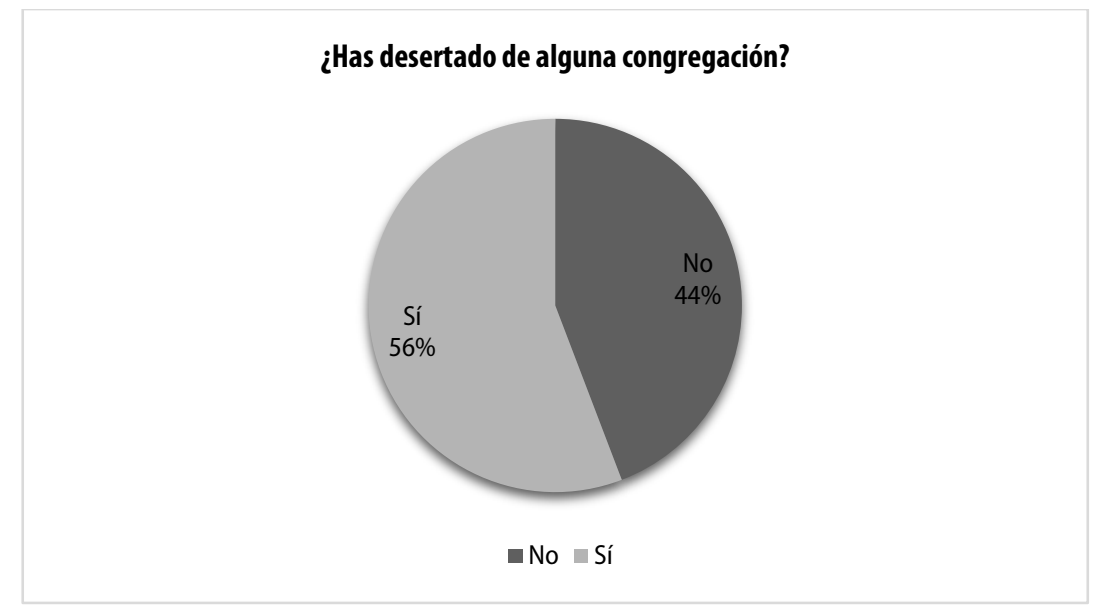

(Fuente: elaboración propia).

Según el gráfico, un 56\% ( $\mathrm{N}=473)$ de los encuestados señala haber desertado alguna vez de una congregación. Evidentemente las razones son múltiples, no obstante, nuestra intención es demostrar que el mundo cristiano-evangélico es una religiosidad donde las relaciones con la institucionalidad se dan en marco de flujos de adscripciones y desafiliaciones constantes.

En términos más específicos, un creyente puede llegar a construir una trayectoria biográfica a partir del tránsito en más de 5 denominaciones -lo que en muchos casos, implica varias iglesias de una misma denominación-, como se observa en la siguiente tabla cruzada:

Tabla 3:

\begin{tabular}{|l|c|c|c|c|}
\hline \multirow{2}{*}{$\begin{array}{l}\text { ¿A cuántas } \\
\text { denominaciones has } \\
\text { pertenecido? }\end{array}$} & $\begin{array}{l}|c| \\
\text { Evangélicos } \\
\text { pneumatocéntricos }\end{array}$ & $\begin{array}{l}\text { Protestantes } \\
\text { históricos y } \\
\text { reformados }\end{array}$ & $\begin{array}{l}\text { Evangélicos } \\
\text { convencionales y } \\
\text { plurales }\end{array}$ & $\begin{array}{l}\text { Ninguna/No } \\
\text { sabe }\end{array}$ \\
\hline Sólo 1 & $4 \%$ & $4 \%$ & $7 \%$ & $2 \%$ \\
\hline Entre 2 y 3 & $1 \%$ & $1 \%$ & $0 \%$ & $0 \%$ \\
\hline Entre 3 y 4 & $0 \%$ & $0,0 \%$ & $0 \%$ & $4 \%$ \\
\hline Entre 4 y 5 & $0 \%$ & $1 \%$ & $0 \%$ & $0 \%$ \\
\hline Más de 5 & $53 \%$ & $36 \%$ & $43 \%$ & $24 \%$ \\
\hline Ninguna & $43 \%$ & $58 \%$ & $51 \%$ & $70 \%$ \\
\hline $\begin{array}{l}\text { Total (por } \\
\text { macrocategorías) }\end{array}$ & $100 \%$ & $100 \%$ & $100 \%$ & $100 \%$ \\
\hline
\end{tabular}

(Fuente: elaboración propia).

Desde este enfoque, los procesos de migración religiosa han sido ampliamente estudiados desde el catolicismo al pentecostalismo, sin embargo, y tal como señala Lindhardt (2016), para comprender a cabalidad el funcionamiento del mercado religioso es necesario poner el foco en las dinámicas de competencia al interior del pentecostalismo, donde los nuevos creyentes se encuentran cada vez más abiertos a cambiar de congregación, las cuales abarcan un amplio espectro en términos de restricciones conductuales y estilos de vida. No obstante, consideramos que la atención no debe reducirse al análisis de los movimientos pentecostales y carismáticos ('Evangélicos 
pneumatocéntricos'), sino más bien extenderse a la interacción entre éstos y las demás ramas protestante-evangélicas. Del resultado de estas interrelaciones y correspondencias se encuentran las claves para la comprensión de la religiosidad cristiano-evangélica contemporánea en su conjunto.

\section{La movilidad y su rol en la creencia}

Llegados a este punto es necesario situar la movilidad como una condición de posibilidad en la adecuación de las creencias individuales en relación de sus adscripciones institucionales. Al respecto, podemos suponer que existe un intenso tránsito prácticosimbólico que es tensionado con los sistemas teológico-doctrinales de cada congregación, una creencia individual que no está completamente determinada por la institucionalidad, en especial respecto a la creencia y vigencia de los Dones del Espíritu Santo, factor configurador de un tipo de identidad carismática propia del mundo pentecostal, quizás el tema más controversial al interior del mundo cristiano-evangélico en la actualidad.

Teológica e históricamente, las posiciones respecto de la manifestación de los Dones de Espíritu Santo se dividen en 4 grandes corrientes: 1) La cesacionista, el cual se define como aquella corriente que sostiene la inexistencia de los Dones en la actualidad. A esta corriente pertenecen gran parte del mundo protestante histórico y reformado, tal como la macrocategoría que propone este artículo. 2) La pentecostal, que aglutina a todos los grupos derivados del avivamiento que comienza en 1901 en Estados Unidos, y que se caracteriza por defender la vigencia de los Dones y la experiencia del Bautismo en el Espíritu Santo, el cual viene acompañado de expresiones sobrenaturales como el hablar en lenguas (glosolalia). 3) La carismática, un movimiento que se manifiesta entre los años 60 y 70, y opera desde dentro de las congregaciones tradicionales como el protestantismo histórico e incluso el catolicismo. 4) La neopentecostal (o Tercera Ola), que emerge en los años 80, la cual sostiene que la proclamación del Evangelio viene acompañada de los Dones (Grudem, 2004, pp. 18-20).

De esta manera, sostenemos que este carácter plural y disperso de creencias se vincula con una tendencia hacia la desestandarización de los grandes núcleos tradicionales doctrinales como agentes organizadores y proveedores de una economía general de sentido en los individuos:

El resultado es que constatamos menos la presencia de universos únicos y homogéneos de significado, que presenciamos un conjunto heterogéneo de fragmentos normativos más o menos personalizados. Esto no impide, por supuesto, el mantenimiento de grandes universos de sentido (...) cada vez más lo que prima es la constatación de mezclas de significado personalizados, y sobre todo, la adhesión plural y transposicional a estos universos. (Martuccelli, 2007, p. 101)

En este contexto, es interesante notar cómo la herencia de la cosmovisión pentecostal, de una u otra forma pervive a lo largo de la trayectoria de vida de una creyente que, habiendo nacido en dicho contexto, en la actualidad adscribe a una iglesia evangélica convencional: 
Con el tiempo, lo que hemos visto que probablemente sea lo que la Biblia llama discernimiento espiritual que no es algo intelectual, no es algo como visible sino que es como un celo de hay un engañador y todos los están dejando, nadie se da cuenta...lo que me ha pasado a mí se extiende más allá de la iglesia, ¿cachai? no es como durante una reunión sino es también para el servicio de otros cristianos, como saber que algo no anda bien (...) [he sentido este discernimiento] con personas...ponte tú hace un año se fue una persona de la iglesia y fue como 'gracias a Dios se fue y no está' porque yo tenía una lucha interna con esa persona, desde lo espiritual. Yo creo que es parte de las cosas que mantienen activa pero no por reconocimiento ni por edificación individual, sino ahora mismo lo vi en la iglesia ${ }^{15}$.

Acá podemos apreciar la presencia del llamado don de discernimiento espiritual, el cual se presenta como un resabio interiorizado en la informante clave. Por lo tanto, su sistema de creencia se entiende como el resultado de una reelaboración racionalizada que concilia elementos teológicos de tradiciones muy distintas. Por ello, la influencia del giro pneumatocéntrico no solamente se expresa en el ámbito teológico-doctrinal sino también en el plano organizacional, tal como se aprecia en la siguiente cita de un informante clave metodista:

Yo creo que (...) lo que hacen las iglesias celulares, de alguna manera es el modelo, yo creo también, o sea, sumado a lo sobrenatural sumado a lo intelectual, que tu casa sea tu iglesia, yo creo que es la única manera porque las relaciones humanas van a quebrar esos estigmas porque es más fácil traer a un loco que nunca pisó la iglesia aquí a que vaya a un culto, que vaya a una vigilia, por muy divertida que sea, por mucho que hayan cosas interesantes no va a ir. Pero acá en una casa por ejemplo, yo creo que es el modelo. Yo creo que es el único modelo que va a servir después, donde tu casa sea la iglesia y cuando esa persona ya se entrega al Señor en la casa, cuando crezca o esté madurando de a poco, recién lo llevai [sic] a la iglesia, recién ${ }^{16}$.

Este testimonio contiene una autocrítica hacia una actual crisis existente en el modelo tradicional de evangelización y la necesidad de generar nuevas asociatividades basadas en los afectos y la confianza como mediadores entre las iglesias y la sociedad inconversa.

En suma, para comprender las transformaciones que ha experimentado el campo religioso cristiano-evangélico contemporáneo es necesario poner nuestra atención en su movilidad endógena donde el pentecostalismo y carismatismo han jugado un rol fundamental como agente catalizador al interior de dicho campo, dinamizando el mercado de bienes de salvación y diversificando la oferta de opciones de sentido. Al mismo tiempo, dichos movimientos han sufrido la influencia tanto de factores externos como desde su propia orgánica: mejoras en las condiciones de vida, mayores niveles de escolaridad en comparación con las generaciones anteriores por un lado; y transformaciones internas como la subjetivación e individualización de lo religioso, y la generación de mecanismos de integración a la sociedad por el otro. Sobre todo estos dos últimos, han ejercido un

\footnotetext{
${ }^{15}$ Informante clave 5: mujer, 33 años, Bioquímico, ex participante activa del Ministerio Vida Estudiantil, miembro de Iglesia Bíblica.

${ }^{16}$ Informante clave 3: hombre, 29 años, Ingeniero, ex líder del Ministerio Águilas de Jesús, miembro de Iglesia Metodista.
} 
importante influjo en la construcción de su identidad colectiva (Mansilla Agüero, 2009), de hecho estas nuevas formas de pentecostalismos contemporáneos adolecen de lo que Mansilla Agüero (2016) denomina el principio pentecostante, el cual alude a una comprensión del movimiento pentecostal como una "protesta religiosa carismática" (p. 30) que se originó en determinadas condiciones socioestructurales de pobreza. Por ello, Mansilla Agüero, Leiva y Muñoz (2017) proponen la noción de pospentecostalismo para diagnosticar este contexto de crisis identitaria. Todo lo anterior, contribuye a la conformación de lo que se ha llamado aquí como desinstitucionalización de lo religioso.

\section{Elementos para una caracterización del creyente desregulado}

Según nuestra encuesta, la desafiliación de iglesias, considerando sus múltiples causas, se concentra desde los 19 hasta los 32 años, como es posible observar en la siguiente tabla, la cual cruza la edad de los creyentes con la deserción de iglesias:

Tabla 4:

\begin{tabular}{|c|c|c|c|c|c|c|c|}
\hline \multirow{2}{*}{$\begin{array}{c}\text { ¿Has desertado de } \\
\text { alguna congregación? }\end{array}$} & \multicolumn{7}{|c|}{ Indique su edad } \\
\cline { 2 - 8 } & $\begin{array}{c}\text { Menos de } \\
18 \text { años }\end{array}$ & $\begin{array}{c}\text { Entre 19 y } \\
25 \text { años }\end{array}$ & $\begin{array}{c}\text { Entre 26 y } \\
32 \text { años }\end{array}$ & $\begin{array}{c}\text { Entre 33 y } \\
40 \text { años }\end{array}$ & $\begin{array}{c}\text { Entre 41 y } \\
47 \text { años }\end{array}$ & $\begin{array}{c}\text { Más de } \\
48 \text { años }\end{array}$ & Total \\
\hline No & $21 \%$ & $32 \%$ & $26 \%$ & $11 \%$ & $9 \%$ & $1 \%$ & $100 \%$ \\
\hline Sí & $20 \%$ & $26 \%$ & $31 \%$ & $11 \%$ & $11 \%$ & $1 \%$ & $100 \%$ \\
\hline Total & $20 \%$ & $29 \%$ & $29 \%$ & $11 \%$ & $10 \%$ & $1 \%$ & $100 \%$ \\
\hline
\end{tabular}

El análisis del segmento etario recién mencionado nos da algunas luces sobre la importancia de este anclaje generacional como agente de transformación cultural, debido a sus niveles de educación formal que los distancia de las generaciones anteriores (Parker, 2005; Fediakova, 2013). Perfilando un tipo particular de creyente al que denominaremos creyente móvil o desregulado. Esta disposición generacional de actitudes más críticas hacia las autoridades la apreciamos en la valoración que los creyentes establecen con sus congregaciones actuales. Se construyó para ello un índice de satisfacción ${ }^{17}$. De los resultados obtenidos, cabe destacar que en aquellos creyentes con algún tipo de movilidad religiosa (deserción de una congregación y pertenencia anterior a una denominación distinta de la actual) presentan niveles de satisfacción menores en comparación a aquellos

\footnotetext{
${ }^{17}$ La evaluación se realizó a partir de una serie de variables que comprenden: el conocimiento teológico que la iglesia manifiesta, la relación entre los hermanos, el liderazgo, su gestión evangelística, la capacidad para abordar temas polémicos, la presencia de espacios destinados para los distintos segmentos de la congregación $y$, finalmente, la capacidad de gestionar los disensos dentro de la comunidad. Cada una de estas variables se expresaron en una escala valórica tipo Lickert de 1 a 5 . Este índice sumatorio simple se construyó a partir del promedio de determinadas categorías relacionadas a aspectos de las congregaciones a las cuales pertenecen actualmente los creyentes: "Conocimiento teológico-doctrinal", "Relaciones entre los demás hermanos", "Liderazgo", "Evangelismo", "Tratamiento de temas "polémicos» a nivel social", "Espacios para diversos grupos (jóvenes, matrimonios, tercera edad, etc.)" y "Capacidad de enfrentar disensiones y diferencias de parte de los creyentes". Expresada en una calificación de 5 valores que van desde "Muy bueno", "Bueno", "Regular", "Malo" y "Muy malo".
} 
que nunca han experimentado ningún proceso migratorio, como se evidencia en estas dos tablas:

Tabla 5:

\begin{tabular}{|c|c|}
\hline $\begin{array}{c}\text { ¿Has desertado de } \\
\text { alguna congregación? }\end{array}$ & $\begin{array}{c}\text { Nivel de Satisfacción } \\
\text { con la congregación } \\
\text { actual }\end{array}$ \\
\hline No & 2,73 \\
\hline Sí & 2,68 \\
\hline
\end{tabular}

\begin{tabular}{|c|c|}
\hline $\begin{array}{c}\text { ¿Has pertenecido a alguna } \\
\text { denominación distinta de la } \\
\text { actual? }\end{array}$ & $\begin{array}{c}\text { Nivel de Satisfacción } \\
\text { con la congregación } \\
\text { actual }\end{array}$ \\
\hline No & 2,74 \\
\hline Sí & 2,66 \\
\hline \multicolumn{2}{|c|}{ (Fuente: elaboración propia). }
\end{tabular}

Al parecer, en los creyentes desregulados, se observa un sentido de mayor exigencia hacia sus líderes y la gestión que éstos despliegan. Resulta sumamente significativo tomar en cuenta que más del $70 \%$ de los encuestados que han migrado, considera que un aspecto fundamental de ser creyente es "congregarse y asistir regularmente a una iglesia". Este dato puede parecer paradójico sin embargo, consideramos que precisamente es la fluidez migratoria un indicador de la importancia de congregarse.

Además, si bien coincidimos con Garma Navarro (2018) sobre la claridad para identificar la movilidad en los creyentes, estimamos que urge preguntarnos cómo tratar de interpretar las causas de la deserción. Por esta razón, en aquellos creyentes con este tipo de movilidad se les consultó sobre las posibles causas de su decisión a través de un conjunto de categorías que intentaron abordar un amplio espectro individual e interpersonal. Destaca entre las opciones con mayor preferencia las "Diferencias doctrinales" con un $46 \%$ seguido de "Conflictos con algún miembro de la congregación" con un $21 \%(\mathrm{~N}=473)$. Los resultados completos se muestran a continuación:

Gráfico 3:

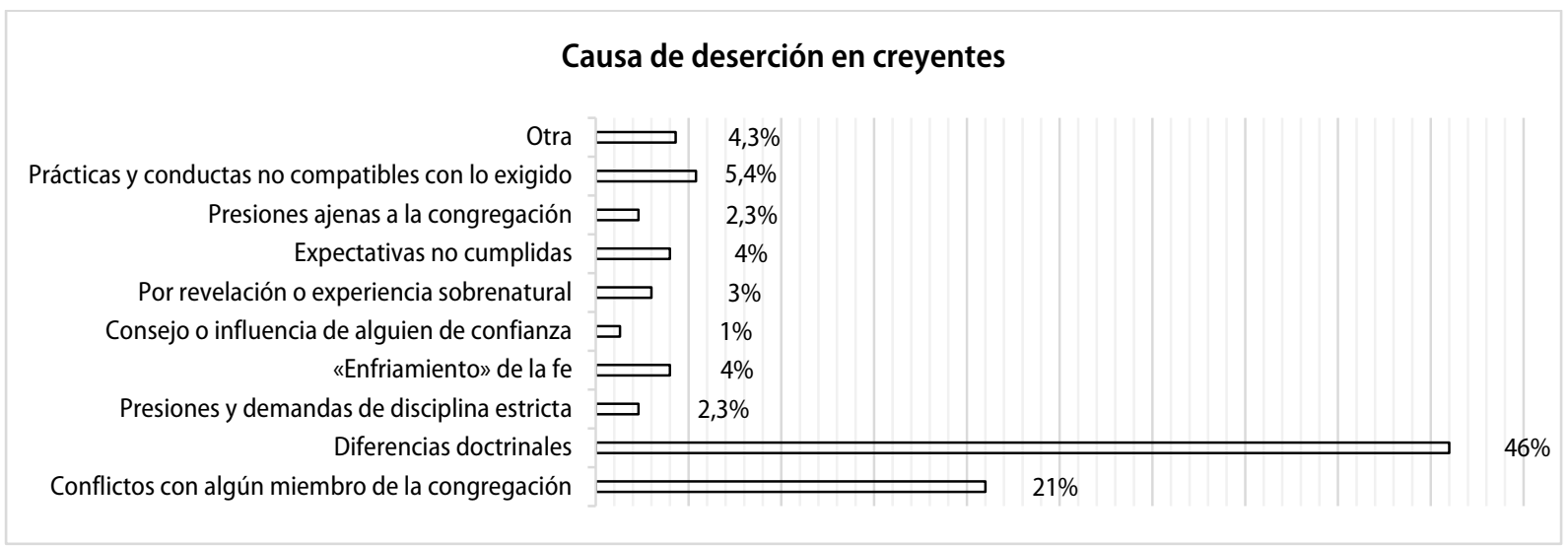

(Fuente: elaboración propia).

Desde la teoría del Rational choice, una deserción por "Diferencias doctrinales" puede interpretarse como una expresión de que las decisiones de los individuos se encuentran orientadas hacia la maximización de utilidades. No obstante, este razonamiento pasa por alto una serie de factores y variables de orden estructural y simbólico (Frigerio, 2000), como por ejemplo la importancia del estatus y las exigencias de roles producto de la 
socialización observadas en el conflicto intergeneracional de jóvenes pentecostales ilustrados, por ejemplo, frente a iglesias cultural y doctrinalmente más tradicionales. De manera complementaria, tanto las deserciones basadas en conflictos interpersonales, la segunda más seleccionada, como en asuntos doctrinales deben enmarcarse dentro de un conjunto de desafíos existenciales (Araujo y Martuccelli, 2010) que son resignificados dentro de los marcos del cristianismo-evangélico, como queda expuesto a continuación:

Durante el verano, me iba a ir de la iglesia, principalmente por un tema que ya no era de amistad, no era una cuestión social porque no tenía ningún problema con ninguna persona, sino que era por un tema teológico. $O$ sea, yo ya me sentaba el día domingo a escuchar al pastor y ya eran cosas que no estaba tolerando porque, por un lado, estaba leyendo un libro de teología que decía una cosa, la cual yo me identificaba, y por otro lado, a la media hora a las 2 horas cuando estaba en la iglesia escuchando al pastor diciendo todo lo contrario ${ }^{18}$.

Desde esta perspectiva, la deserción o desafiliación es un elemento estructurador del creyente como tal, incorporado dentro de su narrativa autobiográfica, parte del proceso de individuación en donde el individuo se configura como sujeto cristiano-evangélico:

Yo creo que fue la obra de Dios no más que hizo en mí...Cuando llegué a Santiago me di cuenta de eso, del amor de Dios, de su Gracia, de su misericordia, de que a pesar de que por ejemplo, el último año yo casi no oraba, no leía la Biblia, no iba a una iglesia, Dios siempre había estado ahí y había sido fiel a pesar de que yo no lo había sido ${ }^{19}$.

La deserción no es un evento espontáneo, sino que es el resultado de una tensión existencial que se gesta con anterioridad y que se vincula con otra de las causas señaladas. Nos referimos a lo que dentro del mundo cristiano-evangélico se conoce como "enfriamiento de la fe", utilizado para designar un periodo de alejamiento del creyente de la vida en comunidad y/o el cultivo de la religiosidad. Así, como se aprecia en la cita, este momento suele ser resignificado en el relato y por lo tanto dotado de un sentido dentro de la trayectoria vital, la cual es entendida como un proyecto de vida donde la religiosidad posee un rol directriz.

Es así como estimamos que el carácter ambivalente de una movilidad motivada por preferencias doctrinales pero que, al mismo tiempo, posibilita la diversificación de creencias movilizadas, constituye uno de los rasgos más evidentes de un divorcio entre individuo e institución, ya que refleja la incapacidad de éste último para proveer un marco estricto de creencias suficientes para ser interiorizadas por el primero. Lo que daría cuenta de la presencia de un cristianismo-evangélico cada vez más desregulado y subjetivado.

Considerando, como ya se mencionó, la prevalencia a la identificación de muchos creyentes como cristianos, muchos de ellos lo definen como un "estilo de vida" más que una religión. Esto debido, precisamente a la oposición implícita entre religiosidad-asociado a lo institucional, tradicional y ritual- y espiritualidad, ésta última como verdadera instancia de

\footnotetext{
${ }^{18}$ Informante clave 6: hombre, 29 años, Profesor de Historia y Geografía, fundador y miembro de Iglesia Bautista Reformada.

${ }^{19}$ Informante clave 4: mujer, 35 años, actriz, ex misionera del Ministerio Vida Estudiantil, Miembro de Iglesia Anglicana.
} 
conexión real y personal con Dios. Estos rasgos ya han sido atestiguados en otras investigaciones en el pentecostalismo chileno (Lindhartd, 2016) pero podríamos plantear la posibilidad de proyectar su impacto en el resto de las demás denominaciones y tradiciones cristiano-evangélicas.

En síntesis, este tipo de creyente desregulado es representativo del campo religioso desinstitucionalizado y se caracteriza por presentar un nivel de autonomía y capacidad crítica ante la autoridad. Por supuesto esta tendencia no constituye un rasgo propio de las nuevas generaciones evangélicas, sino forma parte del cambio cultural que experimentan las sociedades occidentales con la emergencia de los llamados valores posmaterialistas o de la autoexpresión en las últimas décadas (Inglehart, 2001). En este contexto, la movilidad es una expresión de emancipación frente a la institución que refleja la necesidad de un ajuste en sus demandas espirituales.

\section{Conclusiones}

A modo de conclusiones, sostenemos la importancia de analizar las dinámicas de la religiosidad actual bajo un enfoque desde la individuación donde el individuo, en el proceso de su estructuración identitaria como creyente, se construye a sí mismo como un sujeto religioso. Por ello urge establecer una aproximación cada vez más alejada de modelos tradicionales de religiosidad, anclada a teorías de la secularización las cuales no responden a las especificidades de las trayectorias sociohistóricas de América Latina.

Por ello, la gestión de la identidad se comprende como un complejo entramado que está en permannete tensión entre las expectativas de los roles asignados por la comunidad en contraposición a las expectativas del proyecto de vida del sujeto religioso. Por ello, la posibilidad de resignificar experiencias son el reflejo de un marco biográfico-identitario completamente dinámico y en movimiento permanente. Eso es, en definitiva, la identidad cristiano-evangélica.

Podemos concluir entonces que el nivel de diversificación en el campo cristianoevangélico es considerablemente importante, y abre una infinidad de frentes de "combates" por los territorios de creencias. Dentro de esta lógica, el reposicionamiento del protestantismo histórico y reformado se entiende como formas de resistencias a la pentecostalización del evangelicalismo chileno que ha predominado por tantas décadas.

Finalmente, lo que está ocurriendo al interior del campo cristiano-evangélico no es distinto a lo ocurre a otros niveles de la sociedad, respecto de la crisis de confianza y legitimidad entre individuos y sistemas institucionales. Los creyentes desarrollaron procesos de diferenciación, complejización y diversificación de un nivel tal que impide a las instituciones proveer un sentido de identidad integrado en un cuerpo normativo rígido. Esta disociación es posible pesquisarla a distintos niveles (simbólico, práctico, material, cultural y social). 


\section{Reconocimientos}

Los resultados expuestos en el presente trabajo se enmarcan en un proyecto financiado por la fundación ICALA (Intercambio Cultural Alemán-Latinoamericano), denominado: "Migración denominacional al interior del protestantismo chileno: nuevas comunidades, nuevas identidades", realizado en Santiago durante el 2019.

Todos los datos relacionados con la investigación (audios de las entrevistas y sus correspondientes transcripciones), están sujetos a un acuerdo de confidencialidad. El Editor General, de Cuadernos de Teología de la Universidad Católica del Norte, da fe de la existencia de aquellos.

\section{Referencias Bibliográficas}

Algranti, J., Mosqueira, M. y Setton, D. (2019). La institución como proceso. Configuraciones de lo religioso en las sociedades contemporáneas. Buenos Aires: Biblos.

Alloatti, M. (Agosto de 2014). Una discusión sobre la técnica de bola de nieve a partir de la experiencia de investigación en migraciones internacionales. En IV Encuentro Latinoamericano de Metodología de las Ciencias Sociales. Universidad Nacional de Costa Rica, Heredia. https://bit.ly/34Cfu5h

Araujo, K. y Martuccelli, D. (2010). La individuación y el trabajo de los individuos. Educação e Pesquisa, 36 (Especial), 77-91. https://doi.org/10.1590/S1517-97022010000400007

Araya Silva, L. (2017). El malestar en la teoría del sujeto de Guy Bajoit. Castalia, 28(4), 30-38. https://doi.org/10.25074/07198051.4.593

Bahamondes González, L. (2012). Una mirada a la metamorfosis de América Latina: nuevas ofertas de sentido en la sociedad contemporánea. Revista Científica Guillermo de Ockham, 10(2), 109-116. https://doi.org/10.21500/22563202.2362

Bahamondes González, L. y Marín Alarcón, N. (2014). Neopentecostalismos en Chile: transformación y resignificación del pentecostalismo criollo. En L. Bahamondes González (Ed.). Transformaciones y alternativas religiosas en América Latina (pp. 175-191). Santiago de Chile: CISOC-CEJ. https://bit.ly/3aF961i

Bajoit, G. (2003). Todo cambia: análisis sociológico del cambio social y cultural en las sociedades contemporáneas (H. Pozo, Trad.). Santiago: LOM.

Bastian, J.P. (2006). De los protestantismos históricos a los pentecostalismos latinoamericanos: análisis de una mutación religiosa. Revista de ciencias sociales (Iquique. En línea), 16, 38-54. https://bit.ly/37HsFE5

Bravo Vega, F. (Octubre de 2017). Dinamismo pentecostal y reposicionamiento re-formado en el campo evangélico-protestante chileno contemporáneo. En II Congreso Nacional sobre el Fenómeno Religioso en el Mundo Contemporáneo. Centro de Estudios Judaicos, Santiago de Chile. 
Canales, M. (2011). Pentecostalismo: Grupo y autobiografía. En M. A. Mansilla Agüero y L. Orellana Uribe (Eds.). La Religión en Chile del Bicentenario: Católicos, Protestantes, Evangélicos, Pentecostales y Carismáticos (pp. 145-155). Concepción: RELEP.

Cantón Delgado, M. (2002). La construcción social de la sospecha minorías religisas contemporáneas y procesos de exclusión. Estudios sobre las Culturas Contemporáneas, 8(15), 89-111. https://bit.ly/3pshBAZ

Casanova, J. (2007). Reconsiderar la Secularización: na perspectiva comparada mundial. Revista Académica de Relaciones Internacionales, 7, 1-20. https://bit.ly/3psINRf

Centro de Estudios Públicos. (2018). Estudio Nacional de Opinión Pública №82, OctubreNoviembre 2018. Tema especial: Religión. https://bit.ly/34Csloj

Cervantes-Ortíz, L. (2003). Protestantismo, protestantismos e identidad en América Latina y en México. Graffylia, (2), 125-131. https://bit.ly/3ryLuBx

Corvalán, O. (2009). Distribución, crecimiento y discriminación de los evangélicos pentecostales. Cultura y Religión, 3(2), 70-93. https://bit.ly/3aFdHjL

De la Torre, R. (2008). La imagen, el cuerpo y las mercancías en los procesos de translocalización religiosa en la era global. Ciencias Sociales y Religión/Ciências Sociais e Religião, 10(10), 49-72. https://doi.org/10.22456/1982-2650.6709

Fediakova, E. (2013). Evangélicos, política y sociedad en Chile: Dejando "el refugio de las masas" 1990-2010. Concepción: CEEP Ediciones.

Foucault, M. (2014). El gobierno de los vivos. Curso en el Collège de France (1979-1980) (H. Pons, Trad.). Buenos Aires: Fondo de Cultura Económica.

Frigerio, A. (2000). Teorías económicas aplicadas al estudio de la religión: ¿hacia un nuevo paradigma?. Boletín de lecturas sociales y económicas, 7(34), 34-50. https://bit.ly/37LBI72

Gaínza, A. (2006). La entrevista en profundidad individual. En M. Canales (Ed.). Metodología de la Investigación. Introducción a los oficios (pp. 219-263). Santiago: LOM Ediciones.

Garma Navarro, C. (2004). Buscando el espíritu. Pentecostalismo en Iztapalapa y la ciudad de México. México D.F.: Plaza y Valdés.

Garma Navarro, C. (2018). Conversión y movilidad religiosa, propuesta para su análisis. Revista Cultura y Representaciones Sociales, 12(24), 97-130. https://doi.org/10.28965/2018024-04

González, R. (2018). Es casi una experiencia religiosa. Los desafiliados religiosos en Chile. Puntos de Referencia, (499), pp. 1-9. https://bit.ly/2WJZw4Q

Grudem, W. A. (Ed.). (2004). ¿Son vigentes los dones milagrosos?: cuatro puntos de vista (I. López Medel, Trad.). Terrassa: Clie.

Hinzpeter, X. y Lehmann, C. (1999). Mapa de la religiosidad. ¿Cuán religiosos somos los chilenos?.Puntos de referencia, (207), 1-11. https://bit.ly/3mQaznE 
Instituto Nacional de Estadísticas. (2003). Censo 2002: síntesis de resultados. Santiago: INE. https://bit.ly/34JkwwZ

Instituto Nacional de Estadísticas. (2013). Censo 2012: síntesis de resultados. Santiago: INE. https://bit.ly/34J6ag8

Inglehart, R. (2000). Modernización y posmodernización. El cambio cultural, económico y político en 43 sociedades (M. T. Cansado, Trad.). Madrid: Centro de Investigaciones Sociológicas.

Jaimes Martínez, R. (2012). El neopentecostalismo como objeto de investigación y categoría $\begin{array}{llll}\text { analítica. Revista Mexicana de Sociología, 74(4), 649-678. } & \text {. }\end{array}$ https://doi.org/10.22201/iis.01882503p.2012.4.34449

Jungblut, A.L. (2015). Ser evangélico en América Latina. Elementos para un análisis. Nueva Sociedad, 260, pp. 95-108. https://bit.ly/3rueJ8f

Lalive D'epinay, C. (2009). El refugio de las Masas. Estudio sociológico del protestantismo chileno. Concepción: CEEP Ediciones.

Lindhartd, M. (2016). Time to Move On. Pentecostal Church Shifting and Religious Competition in Contemporary Chile. En M. Lindhardt (Ed). New Ways of Being Pentecostal in Latin America (pp. 63-86). Laham, MD: Lexington Books.

Lutero, M. (1520). La Libertad Cristiana. https://bit.ly/3nQZHao

Mansilla Agüero, M. A. (2009). Pentecostalismo y Ciencias Sociales. Reflexión en torno a las investigaciones del pentecostalismo chileno (1968-2008). Cultura y Religión, 3(2), 21-41. https://bit.ly/34FpQBw

Mansilla Agüero, M. A. (2016). La buena muerte. En su La cultura del morir en el pentecostalismo. Santiago: RIL.

Mansilla Agüero, M. A., Leiva, S., y Muñoz, W. (2017). Pospentecostalismo: del fundacionalismo al postfundacionalismo pentecostal chileno. Cinta de moebio, 59, 172-185. https://doi.org/10.4067/S0717-554X2017000200172

Matthes, J. (1971). Introducción a la sociología de la religión (Vol. 2) (A. Sánchez Pascual \& A. Berasáin Villanueva, Trads.). Madrid: Alianza.

Martuccelli, D. (2007). Cambio de rumbo: la sociedad a escala del individuo. Santiago: LOM.

Míguez, D. (2000). Modernidad, postmodernidad y la transformación de la religiosidad de los sectores medios y bajos en América Latina. Revista de ciencias sociales (Iquique. En línea), 10, 56-68. https://bit.ly/37N5GI0

Ossa, M. (2011). La Identidad Pentecostal: Proyecto de futuro. En M. A. Mansilla Agüero y L. Orellana Uribe (Eds.). La Religión en Chile del Bicentenario: Católicos, Protestantes, Evangélicos, Pentecostales y Carismáticos (pp. 155-166). Concepción: RELEP. 
Parker, C. (1993). Otra lógica en América Latina: religión popular y modernización capitalista. Santiago: Fondo de Cultura Económica. https://bit.ly/3hiKvAl

Parker, C. (2005). Pluralismo religioso, educación y ciudadanía. Sociedade e Estado, 23(2), 281-353. https://doi.org/10.1590/S0102-69922008000200005

Pédron-Colombani, S. (2004). Pentecostalismo y transformación religiosa en Guatemala. En J. P. Bastian (Coord.). La modernidad religiosa: Europa latina y América Latina en perspectiva comparada (pp. 175-188). México: Fondo de Cultura Económica.

Pew Research Center. (14 de Noviembre 2014). Religión en América Latina: cambio generalizado en una región históricamente católica (Informe). https://pewrsr.ch/2KP04no

Pontificia Universidad Católica y Adimark. (2018). Religión. En su Encuesta Nacional Bicentenario (pp. 102-123). https://bit.ly/3nRKHcC

Revilla, M. y Carmona, S. (2002). En los tiempos de la identidad: las dimensiones cultural y política de las identidades colectivas. Estudios Políticos, 20, 71-96. https://bit.ly/3nNlqyN

Rolim, F. (1980). Religião e classes populares. Petrópolis: Vozes.

Roy, O. (2010). La santa ignorancia: el tiempo de la religión sin cultura (A. Escartín, Trad.). Barcelona: Península.

Stoll, D. (1990). ¿América Latina se vuelve protestante?: Las políticas del crecimiento evangélico (M. C. Andrade, Trad.). Cayambe: Abya-Yala. https://bit.ly/3aEGN2K

Valenzuela, E., Bargsted, M., y Somma, N. (2013). ¿En qué creen los chilenos? Naturaleza y alcance del cambio religioso en Chile. Temas de la Agenda Pública, 8(59), 1-19. https://bit.ly/3nIUr80

Valles, M. S. (1999). Técnicas cualitativas de investigación social: reflexión metodológica y práctica profesional. Madrid: Síntesis.

Weber, M. (1997). Sociología de la religión (E. Gavilán, Trad.). Madrid: ISTMO.

Willems, E. (1967). Followers of the New Faith: Culture Change and the Rise of Protestantism in Brazil and Chile. Nashville, TN: Vanderbilt University Press.

Wynarczyk, H. (1993). La difusión de iglesias protestantes, evangélicas y pentecostales en la Argentina y el Brasil. Constantes y rupturas. Boletín de lecturas sociales y económicas, 6(27), 71-81. https://bit.ly/3aO3L7A

Para citar este artículo bajo Norma APA 7a ed.

Bravo Vega, F. (2020). Desregulación y movilidad religiosa: dinamismo identitario al interior del campo cristiano-evangélico chileno. Cuadernos de teología - Universidad Católica del Norte (En línea), 12, e4221, https://doi.org/10.22199/issn.0719-81752020-0006

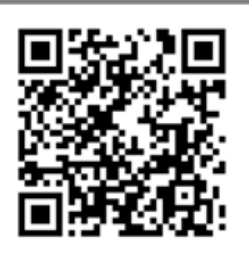

DOI

Copyright del articulo: (2)2020 Fabian Vega

(cc) BY

Este es un artículo de acceso abierto, bajo licencia Creative Commons BY 4.0.

Cuad. teol. - Univ. Catól. Norte (En línea) 2020, 12: e4221 